\title{
O conceito de memória nos anais do capítulo da International Society for Knowledge Organization ISKO-Brasil sob uma perspectiva epistemológica
}

\author{
Keitty Rodrigues Vieira \\ Universidade Federal de Santa Catarina, Departamento de Ciência da Informação, Programa de \\ Pós-Graduação em Ciência da Informação, Florianópolis, SC, Brasil \\ keitty rodriguesvieira@hotmail.com \\ Cezar Karpinski \\ Universidade Federal de Santa Catarina, Departamento de Ciência da Informação, Programa de \\ Pós-Graduação em Ciência da Informação, Florianópolis, SC, Brasil \\ cezar.karpinski@gmail.com
}

DOI: https://doi.org/10.26512/rici.v12.n2.2019.8732

Recebido/Recibido/Received: 2018-06-06

Aceitado/Aceptado/Accepted: 2018-12-12

Resumo: Aborda o conceito de memória nos anais do capítulo ISKO - Brasil a partir de diálogos entre a epistemologia na Ciência da Informação e nos estudos de memória. Investiga sobre os principais conceitos e autores que fundamentam a categoria 'Memória' nos trabalhos publicados nos anais do capítulo da International Society for Knowledge Organization ISKO-Brasil referentes aos anais dos anos de 2012, 2013, 2015 e 2017. Caracteriza-se como uma pesquisa de natureza básica, descritiva, bibliográfica e quantiqualitativa. O termo 'memória' foi buscado no título, palavras-chave e texto completo. Houve duas etapas de análise do corpus, a primeira quantitativa na qual, em 48 documentos, verificou-se os principais conceitos de memória abordados, quantidade de documentos por ano e principais autores citados. Após a aplicação de novo filtro foi possível identificar quais documentos trabalharam os conceitos de memória de maneira mais aprofundada e este corpus de 17 documentos foi submetido a uma análise qualitativa que permitiu comparar a abordagem utilizada nos textos com o que foi apontado na fundamentação teórica deste artigo. Conclui-se que há a necessidade de amadurecimento teórico-conceitual no que tange os estudos sobre memória sob o ponto de vista dos participantes do capítulo ISKO - Brasil.

Palavras-chave: Ciência da Informação. Epistemologia. International Society for Knowledge Organization. Memória.

The memory concept in the analysis of the International Society for Knowledge Organization ISKO Brazil chapter under an epistemological perspective

Abstract: It addresses the concept of memory in the annals of the ISKO - Brazil chapter based on dialogues between epistemology in Information Science and in memory studies. It investigates the main concepts and authors that base the category 'Memory' in the works published in the annals of the International Society for Knowledge Organization ISKO-Brazil chapter referring to the annals of the years of 2012, 2013, 2015 and 2017. It is characterized as a basic research, descriptive, bibliographical and quantitative. The term 'memory' was searched for in the title, keywords and full text. There were two stages of analysis of the corpus, the first quantitative in which, in 48 documents, the main concepts of memory were analyzed, 
number of documents per year and main authors cited. After applying a new filter, it was possible to identify which documents worked the concepts of memory in a more thorough way and this corpus of 17 documents was submitted to a qualitative analysis that allowed to compare the approach used in the texts with what was pointed out in the theoretical foundation of this article. It is concluded that there is a need for theoretical-conceptual maturation regarding memory studies from the point of view of ISKOBrazil chapter participants.

Keywords: Epistemology. Information Science. International Society for Knowledge Organization. Memory.

El concepto de memoria en los anales del capítulo de la International Society for Knowledge Organization ISKO-Brasil en una perspectiva epistemológica

Resumen: Aborda el concepto de memoria en los anales del capítulo ISKO - Brasil a partir de diálogos entre la epistemología en la Ciencia de la Información y en los estudios de memoria. Investiga sobre los principales conceptos y autores que fundamentan la categoría 'Memoria' en los trabajos publicados en los anales del capítulo de la International Society for Knowledge Organization ISKO-Brasil referentes a los anales de los años 2012, 2013, 2015 y 2017. Se caracteriza como una investigación de naturaleza básica, descriptiva, bibliográfica, cuantitativa y cualitativa. El término 'memoria' fue buscado en el título, palabras clave y texto completo. En el presente trabajo se analizaron los resultados obtenidos en el análisis de los resultados obtenidos en el estudio. Después de la aplicación del nuevo filtro fue posible identificar qué documentos trabajaron los concisos de memoria de manera más profunda y este corpus de 17 documentos fue sometido a un análisis cualitativo que permitió comparar el abordaje utilizado en los textos con lo que fue señalado en el texto la fundamentación teórica de este artículo. Se concluye que hay la necesidad de madurar el enfoque teórico-conceptual en los estudios sobre la memoria desde el punto de vista de los participantes del capítulo ISKO - Brasil.

Palabras clave: Ciencia de la Información. Epistemología. International Society for Knowledge Organization. Memoria.

\section{Introdução}

No Brasil, a construção do conhecimento em diversas áreas está integrada às atividades de ensino, pesquisa e extensão universitárias. Nesse sentido, é fundamental discorrer sobre os caminhos por onde se constituem discursos formadores de categorias e conceitos interdisciplinares, principalmente no âmbito geral da Pós-Graduação e específico da Ciência da Informação $(\mathrm{Cl})$. Certamente, um dos conceitos de grande visibilidade para diversas áreas e níveis de formação acadêmica é o de "memória" que, por ser polissêmico, exige constante cuidado na sua definição.

Isto porque, de acordo com Saracevic (1996) e Wersig e Nevelling (1975), as áreas participantes do processo formativo da Ciência da Informação são: Ciência dos Computadores; Biblioteconomia; Filosofia; Taxonomia; Linguística; Teoria da Informação; Cibernética; Matemática; Recuperação da Informação; e Comunicação. Pode-se dizer que as bases epistemológicas da $\mathrm{Cl}$ se constituem na inter-relação destas áreas, o que tem permitido a inserção de profissionais com diversos perfis acadêmicos o que, de certa forma, tem configurado o quadro docente dos Programas de Pós-Graduação na área.

Esta interdisciplinaridade, além de olhares distintos acerca do fenômeno da informação, 
traz novos questionamentos a serem pensados pela $\mathrm{Cl}$ a partir das diversas perspectivas levantadas pelos pesquisadores atuais. Portanto, partindo deste contexto interdisciplinar, o questionamento que norteou a pesquisa foi: 'Como se dá a conceituação teórica de memória nos anais do capítulo ISKO - Brasil?'

O objetivo geral foi o de investigar os principais conceitos e autores que fundamentam a categoria 'Memória' nos trabalhos publicados nos anais do capítulo ISKO - Brasil. Para isso, alguns objetivos específicos foram traçados a fim de nortear a produção deste trabalho. São eles:

a) Apontar as concepções de memória a partir de uma perspectiva epistemológica;

b) Levantar nos anais do capítulo ISKO - Brasil documentos que versem sobre memória;

c) Analisar como o conceito de memória pode ser encontrado, sob a perspectiva epistemológica, nos anais do capítulo ISKO - Brasil.

A justificativa da escolha da temática considera que os debates sobre a categoria "memória", dentro da $\mathrm{Cl}$, vêm sendo elaborados a partir de atividades relacionadas aos cursos de Pós-Graduação. Como exemplo, destacam-se Oliveira e Rodrigues (2010; 2011) e sua importante pesquisa sobre o conceito de memória na $\mathrm{Cl}$ a partir da análise das teses e dissertações brasileiras na área. Dentro da discussão conceitual acerca da memória em suas interconexões com temáticas e subáreas da $\mathrm{Cl}$ pode-se citar também o artigo de Carmo, Karpinski e Bräscher (2018) que discorrem sobre a relação entre o conceito de memória social e da socio cognição no contexto da Organização do Conhecimento.

Além das pesquisas retratadas na produção supracitada, as discussões sobre o conceito de memória também têm se destacado nos Programas de Pós-Graduação em $\mathrm{Cl}$. Por meio de disciplinas específicas, os Programas da Universidade de Brasília (UNB), da Universidade Federal da Paraíba (UFPB) e da Universidade Federal de Santa Catarina (UFSC) vêm fomentando esse debate na área. De um modo geral, essas disciplinas abarcam terminologias, usos, aproximações e possibilidades de pesquisa no viés interdisciplinar que a discussão do conceito exige.

Os estudos sobre memória na $\mathrm{Cl}$ não se restringem às produções das universidades e/ou instituições de ensino somente. Além da discussão conceitual a que este artigo se soma, devem ser referenciadas ainda as pesquisas que se desenvolvem a partir das formas adjetivadas do conceito de memória. Nesse caso, é exemplo o trabalho de Brito (2003) que "aborda o tema da memória científica e tecnológica, e sua preservação, num contexto específico, a Fundação Oswaldo Cruz". Nesta abordagem específica, o conceito de memória se refere a um tipo de instrumentalização prática a partir da sua intrínseca relação com a documentação. Isto porque, de acordo com esta autora, a memória científica se encontra

também nos arquivos gerados no decorrer de atividades que viabilizam e possibilitam o fazer científico e naqueles decorrentes de atividades que são 
essenciais à atividade científica, como a difusão da ciência levada a efeito pelas revistas especializadas e pelos grandes bancos de dados que referenciam a produção científica nacional e internacional. (BRITO, 2003, p. 2)

Portanto, para identificar o conceito de memória na $\mathrm{Cl}$ é preciso considerar os locais que abarcam as memórias científicas da área. Sendo assim, entende-se que os estudos acerca da memória se estendem também aos eventos científicos da área, como os trabalhos apresentados, por exemplo, no Grupo de Trabalho 10 - Informação e Memória da Associação Nacional de Pesquisa e Pós-Graduação em Ciência da Informação (ANCIB). Além disso, considerando a existência do capítulo brasileiro da International Society for Knowledge Organization (ISKO) que permite a reunião de profissionais de diversas áreas como Ciência da Informação, Filosofia e História, percebeu-se que a produção científica divulgada nos eventos ISKO pode ser vista como um ponto de partida sobre as distintas abordagens sobre o conceito, mesmo a discussão se dado na interface da Organização e Representação do Conhecimento. Por este motivo se justifica a utilização dos anais do capítulo ISKO - Brasil como fonte para a coleta de dados e análise desta pesquisa.

O presente trabalho encontra-se dividido em cinco seções, incluindo a introdução. A segunda seção apresenta a fundamentação teórica que embasa a discussão deste estudo, apresentando, portanto, a epistemologia da Ciência da Informação e a fenomenologia da Memória. Em seguida, na terceira seção serão apresentadas as opções metodológicas que possibilitaram a coleta de dados do corpus analisado. A análise e discussão dos resultados encontram-se na seção de número quatro e as considerações finais são discutidas na seção de número cinco.

A análise do presente estudo permite concluir que os estudiosos da Organização do Conhecimento não se aprofundam no conceito de memória, o que ocasiona uma pluralidade de entendimentos sobre o tema. No entanto, o último capítulo ISKO-Brasil, de 2017, que trouxe como tema "Memória, Tecnologia e Cultura na Organização do Conhecimento" abriu espaço para que diálogos teóricos mais consistentes sejam realizados dentro do escopo da Organização do Conhecimento. Isto possibilita, de acordo com as análises, um estreitamento entre os debates dos estudiosos da área de memória com os demais pesquisadores interessados no assunto. Conclui-se que tal assunto não demonstra só uma fragilidade conceitual, mas que aponta para direções de investigações específicas sobre a temática de memória, tanto do ponto de vista conceitual/teórico, quanto de estudos de caso/aplicação do conceito.

\section{$2 \mathrm{O}$ conceito de memória como problema epistemológico em $\mathrm{Cl}$}

A Ciência da Informação se constituiu a partir das mudanças oriundas da Segunda Guerra 
Mundial e o fomento ao desenvolvimento científico e tecnológico, como já é de conhecimento dos pesquisadores da área. Conforme afirmam Freire e Carvalho Silva (2012, p. 164), as incertezas e a diversidade de áreas envolvidas com o processo de constituição da $\mathrm{Cl}$ implicam em uma dificuldade de "concepção global da informação e, por conseguinte, a construção de uma epistemologia na Ciência da Informação".

Carvalho Silva (2016), apresenta dois fenômenos que, para o autor, seriam responsáveis pela constituição da $\mathrm{Cl}$ : o primeiro diz respeito à apropriação de teorias das áreas distintas que fizeram parte do processo formativo da $\mathrm{Cl}$ e; o segundo fenômeno, estaria relacionado com a adaptação dessas teorias com o foco em sua aplicabilidade. Sendo assim, neste segundo fenômeno, encontra-se espaço para discussões acerca da Gestão/Política/Economia da informação, Tecnologias da Informação e o próprio debate epistemológico já que tal fenômeno só acontece a partir de reflexão e análise crítica das teorias anteriormente apropriadas de modo a adaptá-las permitindo sua aplicabilidade dentro das unidades de informação.

Apresentando um olhar mais aprofundado sobre a epistemologia da Ciência da Informação, Souza (2011) comenta que na década de 1970 iniciam-se os estudos reflexivos sobre a $\mathrm{Cl}$ e que, consequentemente, a área passou a adotar modelos epistemológicos para seu escopo. Em princípio, perceberam-se inconsistências epistemológicas na Ciência da Informação, por ser uma ciência que se pauta em bases epistemológicas de diversas ciências.

No entanto, o fato de não ter "uma" base epistemológica nos termos definidos conceitualmente como sendo de epistemologia, foi evidenciada a identidade interdisciplinar do campo. Saracevic (1996) destaca que é a interdisciplinaridade da Ciência da Informação sua principal característica e que isto não a prejudica com relação à sua constituição epistemológica. Contudo, há que se possa certo cuidado na formulação de um discurso epistemológico e deve se considerar os aspectos históricos que permeiam esse processo construtivo, principalmente no que se refere aos usos de categorias de análise ou conceitos comumente utilizados pelas áreas afins à $\mathrm{Cl}$.

Este deve ser o cuidado, por exemplo, com o uso do conceito de memória. Em termos teóricos, esta categoria pode ser abordada a partir de distintas perspectivas que ora se complementam, ora se enfrentam, mas que, nem por isso, perdem qualidade de discussão. Dentro da $\mathrm{Cl}$, devido às unidades de informação como bibliotecas, arquivos e museus, é recorrente a tentativa de aproximação do conceito de memória com a informação.

De acordo com Melo Filho (2016), o mundo passa a ser visto sob a perspectiva de um espaço informacional e memorial a partir do Século XX. Para Pereira, Serafim e Molina (2016), quando a memória é tratada como informação, ela adquire um caráter interdisciplinar. Este, por sua vez, possibilitaria o diálogo com a Biblioteconomia, Arquivologia, Museologia, mas também poderia adquirir outras formas de abordagem quando estudada por diferentes áreas do 
conhecimento como a Filosofia, História e Sociologia.

Para os interesses deste artigo, optou-se em exemplificar o uso da categoria memória a partir do debate proposto por Carmo, Karpinski e Bräscher (2018) naquilo que se refere especificamente à história do conceito de memória. A categoria memória, para esses autores, pode ser observada por meio de três concepções distintas promulgadas entre os séculos XIX e XX, cada uma delas defendida por um autor: memória individual de Henri Bergson em fins do Século XIX; memória coletiva de Maurice Halbwachs, na metade do Século XX; e memória social de James Fentress e Cris Wickham, na década de 1990.

Henri Bergson (1859-1941), na célebre obra "Matéria e memória" publicado originalmente em 1896, foi o filósofo que abriu um diálogo acerca da fenomenologia da memória como fator determinante no processo de cognição humana. Para Bergson (2010), a epistemologia - entendida como área da filosofia que se dedica à compressão de como ocorre o conhecimento humano - desconsiderou a importância ou determinação dos fenômenos lembrar e esquecer na composição cognitiva do homem. Por ser um fenômeno interior e que ocorre tanto por mecanismos psíquicos quanto por fatores reflexivos do sujeito do conhecimento, as representações miméticas foram denominadas no âmbito individual.

O filósofo ainda discute sobre dois tipos de memórias "das quais uma imagina e a outra repete, a segunda pode substituir a primeira e frequentemente até dar a ilusão dela" (2010, p. 89, grifo do autor). Essa segunda memória estaria atrelada àquilo que o homem concebe por meio da experiência e que não reflete o fato ocorrido, mas sim, prolonga o efeito daquele fato até o momento presente. Nesse sentido, como também perceberam Carmo, Karpinski e Bräscher (2018), foi a partir de Bergson que a memória passou a ser entendida como um fenômeno do presente e não do passado. Isto porque, na compreensão de Bergson, é sempre no momento atual que o sujeito constrói suas referências e representações do passado.

Contudo, esse caráter individual da memória no pensamento bergsoniano foi compreendido como individualista e traduzido por seus críticos como um procedimento introspectivo, romântico e não aplicável socialmente. Foi criticando o conceito de memória individual que o principal crítico de Bergson, seu aluno Maurice Halbwachs, cunhou um dos conceitos mais utilizados em pesquisas que se relacionam de alguma forma com a memória: o conceito de memória coletiva. De acordo com Halbwachs (2006), toda memória individual seria apenas um ponto de vista sobre a memória coletiva, esta última formulada a partir da relação de determinado grupo inserido num contexto que destaca as lembranças presentes em eventos comuns à maioria desses membros.

Baseado no método sociológico durkheimiano, Halbwachs afirma que, independente da intensidade que tais lembranças possuem para cada indivíduo, é a memória coletiva que 
permanece viva. Nesse sentido, a memória coletiva determina as memórias individuais que podem ser mutáveis com base na relação tanto da memória coletiva quanto individual com outros ambientes. Ao historiar a compreensão fenomenológica da memória a partir da histórica do conceito, Ricoeur (2007) cita Halbwachs e o coloca como um dos grandes teóricos neste assunto.

Deve-se a Maurice Halbwachs a audaciosa decisão de pensamento que consiste em atribuir a memória diretamente a uma entidade coletiva que ele chama de grupo ou sociedade. Na realidade ele já havia forjado o conceito de 'quadros sociais da memória' antes de $A$ Memória coletiva. Na época, era na condição de sociólogo puro, e na esteira de Émile Durkheim, que ele designava a memória em terceira pessoa e lhe atribuía estruturas acessíveis à observação objetiva. [...] 0 texto diz fundamentalmente isto: para se lembrar, precisa-se dos outros. (RICOEUR, 2007, p. 130, grifo do autor)

Entretanto, o conceito de memória coletiva de Halbwachs acaba homogeneizando o fenômeno da lembrança e do esquecimento, tirando do indivíduo o grau de liberdade que a ele compete tanto no lembrar, quanto no esquecer. Nesse sentido, o conceito de memória coletiva, embora comumente utilizado ainda hoje, desconsidera o lugar que o próprio conceito de memória ocupa na sociedade: o de disputa. Com bem apontaram Carmo, Karpinski e Bräscher (2018), o principal crítico da teoria halbwachsiana de memória coletiva é o historiador Michel Pollak. Pollak (1989), ao estudar as influências da segunda guerra mundial na constituição da memória e da história da Europa Ocidental pós-guerras, afirma que o conceito de memória coletiva serviu para a consolidação de uma história oficial, nacional e homogênea que desconsiderou todos aqueles que não se fizeram presente nas "memórias coletivas".

\footnotetext{
Na abordagem durkheimiana, a ênfase é dada à força, quase institucional, dessa memória coletiva, à duração, à continuidade e à estabilidade. Assim também Halbwachs, longe de ver nessa memória coletiva uma imposição, uma forma específica de dominação ou violência simbólica, acentua as funções positivas desempenhadas pela memória comum, a saber, de reforçar a coesão social, não pela coerção, mas pela adesão afetiva ao grupo, donde o termo que utiliza, de "comunidade afetiva". Na tradição européia do século XIX, em Halbwachs, inclusive, a nação é a forma mais acabada de um grupo, e a memória nacional, a forma mais completa de uma memória coletiva. (POLLAK, 1989, p. 3)
}

Essa crítica de Pollak, feita na década de 1980, alertou para o fato que nem todas as pesquisas que se voltam para os processos de memória ou esquecimento podem se valer do conceito de memória coletiva como fundamento e categoria de análise. Isto porque o processo de constituição da memória coletiva pode ser permeado pelos princípios de exclusão, segregação e marginalização daqueles que determinada coletividade quer "apagar da memória" e, consequentemente, da história.

Baseado nesse processo crítico de constituição conceitual sobre a memória, Fentress e 
Wickham (1998) propõe o conceito de "memória social". De acordo com Peralta (2007, p. 7), Fentress e Wickham procuram evitar "uma excessiva sujeição do indivíduo a um determinismo coletivo na linha da escola durkheimiana" e, por isso, os adotam o termo "memória social".

Fentress e Wickham (1998) comentam que os grupos devem ser situados em relação ao seu contexto e suas próprias tradições, o que demonstra a construção da memória social a partir das verdades individuais dos membros de determinado grupo. Além disso, os autores afirmam que a "a memória social é uma fonte de conhecimento. [...] Ela também fornece ao grupo material para reflexão consciente" (FENTRESS; WICKHAM, 1998, p. 26, tradução livre).

Na área de Ciência da Informação, Carmo, Karpinski e Bräscher (2018) propõem o conceito de memória social de Fentress e Wickham no contexto da Organização do Conhecimento. Os autores relacionam o papel da memória na constituição da cognição e produção do conhecimento a partir de uma perspectiva social. Nesse sentido, os conceitos de "memória social" e "sociocognição" se tornam instrumentos coerentes para novas reflexões sobre produção, consumo e organização do conhecimento. O estudo de Carmo, Karpinski e Bräscher (2018) fornece subsídios para a organização do conhecimento no que diz respeito às formas como as comunidades discursivas produzem e organizam seus conhecimentos socialmente construídos.

Esse breve percurso histórico do conceito de memória em suas variáveis mais comuns deslinda a necessidade de aprofundamento teórico constante e de posicionamentos claros acerca das perspectivas que embasam sua escolha. Entende que o fator interdisciplinar da Ciência da Informação, ao mesmo tempo em que Ihe concede a liberdade de transitar em campos conceituais de diversas áreas do conhecimento, impõe a necessidade de conhecimento sobre a história destes conceitos. Com base nesta explanação, buscou-se levantar as formas de abordagem conceitual sobre a categoria "memória" em um dos canais de comunicação científica da área, o que será apresentado nos itens a seguir.

\section{Opções metodológicas}

O presente artigo pode ser caracterizado como uma pesquisa de natureza básica, descritiva, bibliográfica e quanti-qualitativa. A coleta de dados foi realizada a partir dos anais publicados do capítulo ISKO - Brasil, referentes aos anos de 2012, 2013, 2015 e 2017 e o acesso a esse material se deu no mês de Março de 2018.

Para a formação do corpus de análise, buscou-se o termo 'memória' nas palavras-chave, no título e no texto completo. A partir desses dados foi feita uma análise quantitativa quanto a ocorrência do termo, permitindo, portanto, o levantamento dos conceitos utilizados sobre memória e os principais autores citados para sua conceituação. Nesta etapa, o corpus de análise contou com 48 documentos. 
No segundo momento, partiu-se para uma abordagem qualitativa, com a leitura de todos os artigos, pela qual foram identificadas convergências e divergências dos conceitos e autores apresentados com o referencial teórico sobre memória abordado neste artigo. No entanto, considerando que muitos dos documentos apenas mencionam o termo "memória" e não oferecem embasamento teórico sobre o mesmo, o número de documentos que serviram para os objetivos da pesquisa reduziu drasticamente para 17 documentos. Essa redução do número de artigos passíveis de análise no âmbito conceitual reforça a justificativa deste estudo, pois mostra o nível de discussão teórica ou a sua ausência, como no caso dos 31 artigos que, mesmo utilizando o conceito de memória, não o definem ou não se posicionam quanto à perspectiva de análise adotada.

\section{Análise e discussão dos resultados}

$\mathrm{Na}$ fase quantitativa desta pesquisa, o levantamento do corpus por meio da busca do termo 'memória' possibilitou a coleta de 48 documentos presentes nos anais do capítulo ISKOBrasil, nos anos de 2012, 2013, 2015 e 2017. No Gráfico 1 é possível verificar a quantidade de documentos encontrados de acordo com o ano.

Gráfico 1 - Quantidade de documentos recuperados por ano

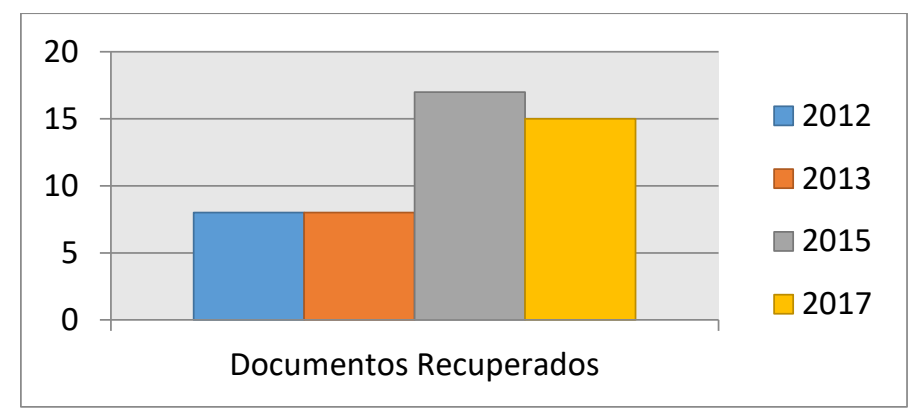

Fonte: Dados da pesquisa, 2018.

Percebe-se um aumento significativo de publicações entre 2013, que havia 8 documentos, e 2015, já com 17 textos mencionando o termo "memória". Embora haja uma diminuição de publicações no ano de 2017, o volume ainda pode ser considerado alto se comparado aos dois primeiros anais da ISKO - Brasil e a diminuição da quantidade de menção ao termo pesquisado não é sinônimo de baixa qualidade do material.

Com relação à ocorrência do termo "memória" nos textos, nota-se um grande aumento no último ano analisado, o que é compreensível dada a temática da ISKO-Brasil 2017 que era "Memória, Tecnologia e Cultura na Organização do Conhecimento", fato este que pode ser visualizado por meio do Gráfico 2. 
Gráfico 2 - Ocorrência do termo 'memória' no corpus

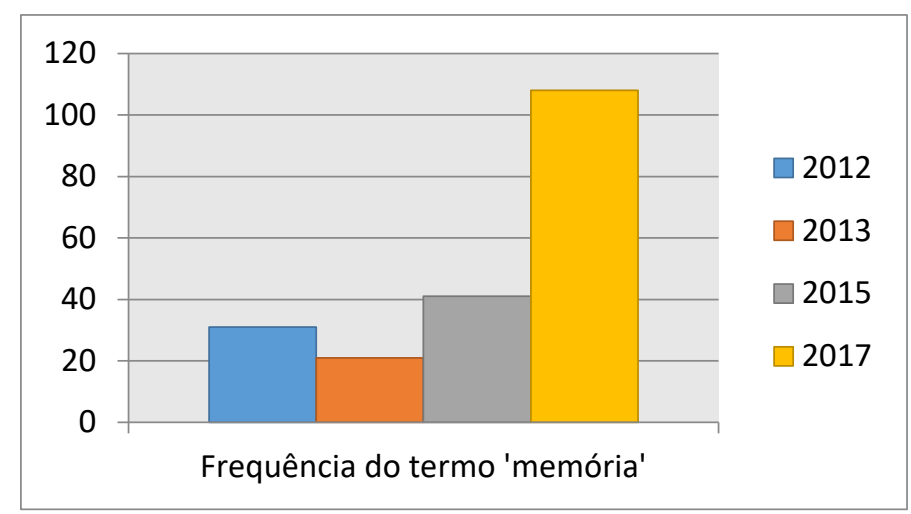

Fonte: Dados da pesquisa, 2018.

Quanto aos conceitos mais utilizados, verifica-se que em grande parte das menções, o termo "memória" está relacionado a nomes de programas de pesquisa, abas de site e nomes de institutos, dado este que, embora seja colocado no presente estudo, não configura aquilo que se busca nesta pesquisa, pois não envolve uma discussão teórica acerca do conceito de "memória".

Outro dado importante é que, embora 31 dos 48 documentos não façam discussão ou se posicionem teórico-conceitualmente acerca da "memória", há a menção às temáticas de memória individual, coletiva, social e documental. Além disso, também são encontrados menções às unidades de informação como bibliotecas, arquivos e museus enquanto lugares ou instituições de memória, conforme apresenta o Gráfico 3.

\section{Gráfico 3 - Frequência das temáticas encontradas no corpus}

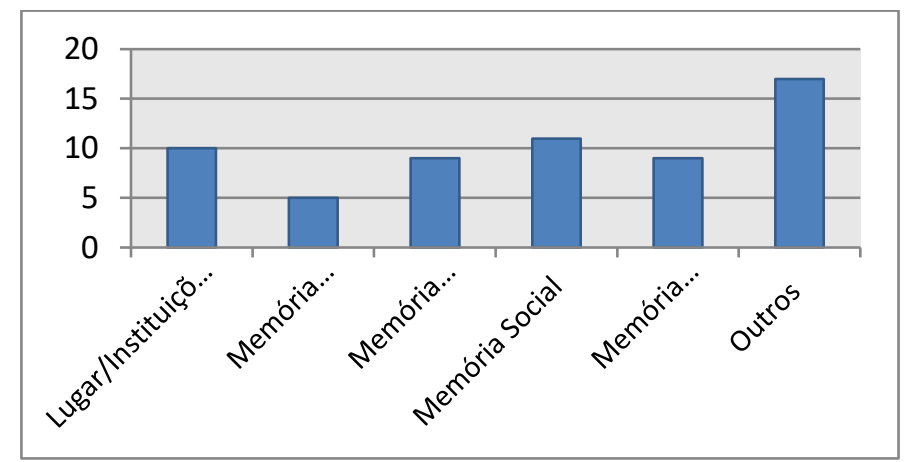

Fonte: Dados da pesquisa (2017)

A análise dos autores mencionados quando se utiliza o termo "memória" revelou que não há nenhum padrão de embasamento teórico justamente pela falta de aprofundamento conceitual. Os únicos autores citados em mais de um documento são Birger Hjørland (2008) que coloca as bibliotecas, arquivos e museus enquanto instituições de memória e a classificação indireta de Francis Bacon que se divide em razão, imaginação e memória. No entanto, as 
concepções de Hjørland e Bacon não sofreram análises críticas por parte dos autores do corpus.

Na segunda etapa da pesquisa, buscou-se verificar pontos de convergência e divergência da conceituação do termo "memória" com relação à fundamentação teórica presente neste artigo. Para tal, os 17 documentos que compõem este segundo corpus de análise foram lidos na íntegra e, a seguir, apresentam-se sínteses dessa análise.

Por meio da leitura dos textos é possível perceber a forte ligação da memória com a preservação da cultura e da história de uma determinada comunidade. A importância da conservação dos documentos e a noção de patrimônio como meio de preservação da memória é uma temática comum nos estudos dentro do capítulo ISKO - Brasil. Contudo, de acordo com a literatura levantada na fundamentação deste artigo, percebe-se que não necessariamente os estudos da memória devem estar atrelados à História ou à massa documental.

Também se verificou que o conceito de memória social como sendo um elo que abarca a memória coletiva. Esta última, por conseguinte, seria a 'junção' de memórias pessoais, que também entendemos como memórias individuais. Embora Bergson, Halbwachs, Fentress e Wickham não tenham sido citados pelos autores do corpus, essa concepção de que a memória individual contribui para a construção da memória coletiva e que, consequentemente, a memória coletiva auxilia no processo formativo de uma memória social vai ao encontro do que grandes teóricos estudiosos da memória afirmam.

Neste mesmo sentido, Duarte (2009, p. 306, apud MARTINS; AZEVEDO NETTO, 2012, p. 122) complementa que "essa memória coletiva é a memória da sociedade, formada por micro memorias pessoais, sendo um elo de uma cadeia maior, a memória social, e onde ocorre uma totalidade significativa da representação do patrimônio". Martins e Azevedo Netto (2012) ainda mencionam que as memórias documentárias são fontes de estudos da Ciência da Informação considerando que a informação seria o grande objeto de estudo desta área.

Muitos dos documentos analisados relacionam a preservação da memória com atividades de recuperação da informação e de gestão arquivística, o que permite inferir que, de fato, há alguns estudos da Arquivologia, Biblioteconomia e Museologia, que podem contribuir e se beneficiar com os estudos conceituais sobre a "memória". Estes estudos podem variar desde a construção histórica da realidade de determinado grupo, até aos avançados estudos sobre a preservação digital. Esta última no sentido de garantir a continuidade e a construção de memórias institucionais por meio documental, lembrando que esses documentos podem variar entre produções textuais, documentos arquivísticos, tridimensionais e fotografias além de, é claro, os nascidos digitais.

Pinto e Ribeiro (2017) trazem para os estudos da Organização do Conhecimento o autor Pierre Nora, historiador francês que, nos estudos sobre a memória, trabalha com o conceito de 
Lugares de memória. Embora os demais textos do corpus que tratam arquivos, bibliotecas e museus enquanto lugares de memória não mencionem a conceituação de Nora, infere-se que o entendimento desses autores vai ao encontro da fala de Nora (1993, p. 12-13) que diz que "os lugares de memória são, antes de tudo, restos. [...] Museus, arquivos, cemitérios e coleções, festas, aniversários, tratados, processos verbais, monumentos, santuários, associações, são os marcos testemunhas de uma outra era, das ilusões de eternidade"; e ainda complementa que

os lugares de memória nascem e vivem do sentimento que não há memória espontânea, que é preciso criar arquivos, que é preciso manter aniversários, organizar celebrações, pronunciar elogios fúnebres, notariar atas, porque essas operações não são naturais. (NORA, 1993, p. 13)

Medeiros e Pinho (2017), ao trabalhar a representação da informação em obras artísticopictóricas se utiliza da concepção de memória coletiva e individual adotada por Jacques Le Goff (1924 - 2014). Os autores mencionam que essa concepção de Le Goff permite

relacionar os movimentos de arte e a própria produção artística como representações da coletividade e da individualidade do homem, onde, numa perspectiva coletiva, demonstram em suas construções estéticas e significativas, elementos de identidade ao criar representações pelas obras de arte, e também pela apreciação dos espectadores que, nas suas individualidades fazem a leitura e o reconhecimento dos signos indenitários representativos do meio social como um todo. (MEDEIROS; PINHO, 2017, p. 298)

No entanto, Le Goff não pode ser considerado um "teórico" da memória, uma vez que nada mais faz que "comentar" os conceitos cunhados por autores como Bergson, Halbwachs e Nora, por exemplo. A preocupação de Le Goff (1990) é o de distinguir Memória de História e, para isso, se utiliza de instrumental teórico coerente com sua posição disciplinar, mas é um autor que deveria ser considerado secundariamente nas discussões teóricas acerca da memória. O fato de ser Le Goff (1990) servir de fundamente teórico para estudos da área de $\mathrm{Cl}$ também é um indicativo da necessidade de introdução de autores que servem de referência conceitual tais como Bergson, Halbwachs, Fentress e Wickham, Pollak, Nora e, nos últimos anos, Ricouer, todos já citados neste artigo.

Isto posto, verificou-se que, de maneira geral, os artigos analisados não se posicionam ou aprofundam o referencial teórico sobre o conceito "memória", o que deveria ser feito tendo em vista a polissemia do próprio conceito. Entende-se que o conceito ou o fenômeno da memória não seja o principal objeto de estudo da área de Ciência da Informação. Contudo, os estudiosos devem adotar uma postura coerente com as áreas que há décadas estudam, publicam e discutem especificamente o fenômeno da memória na constituição da sociedade ocidental.

Por isso a necessidade constante de amadurecimento teórico e o debruçar sobre os 
autores 'referência' na temática, pois isto permitirá um maior avanço na solução de problemas de pesquisa. No entanto, o aumento da produção científica acerca da temática também possibilita inferir que, pouco a pouco, os estudos da memória inserem-se no contexto da Organização do Conhecimento de forma positiva, pelo menos no tange aos debates propiciados pelos capítulos ISKO - Brasil.

\section{Considerações finais}

Embora a produção científica dos anais do capítulo ISKO - Brasil reflita o uso do termo "memória" e ainda apresente um aumento gradativo no decorrer dos anos, conclui-se que o conceito de "memória" ainda não foi aprofundado pelos estudiosos da Organização do Conhecimento o que, consequentemente, repercute na pluralidade de entendimentos, muitos deles incoerentes com as perspectivas teóricas acerca do tema.

Entende-se que há um forte envolvimento das questões de memória na atuação cientista da informação. Os profissionais da informação, ao gerenciarem seu acervo, além de o disponibilizarem aos usuários também participam da constituição e/ou manutenção da memória institucional. Nesse sentido, compreender os conceitos, as vertentes e o debate acerca de um termo polissêmico e interdisciplinar como o de "memória" contribui para futuras reflexões.

Contudo, entende-se que o capítulo 2017, cujo tema foi “Memória, Tecnologia e Cultura na

Organização do Conhecimento" possibilitou diálogos mais consistentes com relação à memória e, inclusive, trouxe bibliografia especializada com a inserção de estudiosos como Le Goff e Pierre Nora. Por mais que estes dois autores não sejam teóricos de referência sobre o assunto, são, em grande medida, bons comentadores e analistas do conceito no escopo disciplinar em que estão inseridos, no caso a História.

Percebe-se, portanto, a amplitude de intersecções possíveis para futuros debates a partir da fenomenologia da memória e da epistemologia da Ciência da Informação. Contudo, embora o aprofundamento teórico baseado em estudiosos inseridos especificamente no campo da memória possibilite um maior enriquecimento da produção científica na área da Ciência da Informação, percebe-se que no contexto de análise dos anais do capítulo ISKO - Brasil, ainda há muito que se construir.

\section{Referências}

BERGSON, Henri. Matéria e memória: ensaio sobre a relação do corpo com o espírito. 4. ed. São Paulo: WMF M. Fontes, 2010. 291 p.

BRITO, Verônica Martins de. A preservação da memória científica da Fiocruz: a visão de quem faz ciência. In: ENCONTRO NACIONAL DE PESQUISA EM CIÊNCIA DA INFORMAÇÃO, 5., 2003, 
<http://enancib.ibict.br/index.php/enancib/venancib/paper/viewFile/1928/1069>. Acesso em: 21 nov. 2018.

CARMO, Juliana Rabello; KARPINSKI, Cezar; BRASCHER, Marisa. A relação entre a memória social e sociocognição: busca do contexto social na Organização do Conhecimento. Em Questão. Porto Alegre, v. 24, n. 1, p. 65-85, 2018 . Disponível em: <http://seer.ufrgs.br/index.php/EmQuestao/article/view/ 71083/43768>. Acesso em: 13 mar. 2018.

CARVALHO SILVA, Jonathas Luiz. Tópicos em biblioteconomia e ciência da informação: epistemologia, política e educação. Rio de Janeiro: Agência Biblioo, 2016. 124 p.

FENTRESS, James; WICKHAM, Chris. Social Memory: New perspectives on the past. Cambridge, MA: Blackwell Publisher, 1998.

FREIRE, Gustavo Henrique de Araújo; CARVALHO SILVA, Jonathas Luiz. A configuração do campo da Ciência da Informação: marcas de uma identidade. Informação \& Sociedade: Estudos, João Pessoa, v. 22, p. 161-174, Número Especial, 2012. Disponível em: <http://www.ies.ufpb.br/ ojs/index.php/ies/article/view/13775/8216>. Acesso em: 27 abr. 2017.

HALBWACHS, Maurice. A memória coletiva. 2. ed. São Paulo: Centauro, 2006. 222 p.

HJORLAND, Birger. What is knowledge organization (KO)? Knowledge Organization, v. 35, n. 2/3, p. 86-101, 2008. Disponível em: <https://is.muni.cz/el/1421/jaro2016/VIKBA06/um/ 56249939/HJORLAND_Birger._What_is_knowledge_organization_KO_.pdf $>$. Acesso em: 18 mar. 2018.

LE GOFF, J. História e memória. Campinas: Editora da Unicamp, 1990. Disponível em: <http://memorial.trt11.jus.br/wp-content/uploads/Hist\%C3\%B3ria-e-Mem\%C3\%B3ria.pdf>. Acesso em: 19 mar. 2018.

MARTINS, Gracy Kelli; AZEVEDO NETTO, Carlos Xavier de. Representação da informação e preservação da memória: Mapeamento conceitual do patrimônio imaterial brasileiro. In: CONGRESSO BRASILEIRO EM ORGANIZAÇÃO E REPRESENTAÇÃO DO CONHECIMENTO, 1., 2012, Marília. Anais... . Marília: ISKO - Brasil; Fundepe, 2012. p. 122 - 136. Disponível em: <https://www.marilia.unesp.br/Home/Extensao/CEDHUM/livro-isko-brasil-finalizado.pdf>.

Acesso em: 19 mar. 2018.

MEDEIROS; Wagner Oliveira de; PINHO, Fabio Assis. O uso de mapas conceituais na representação da informação memorialística de obras artístico-pictóricas. In: CONGRESSO BRASILEIRO EM ORGANIZAÇÃO E REPRESENTAÇÃO DO CONHECIMENTO, 4., 2017, Recife. Anais... . Recife: ISKO - Brasil; Ed. UFPE, 2017. p. 297 - 305. Disponível em: < http://iskobrasil.org.br/wp-content/uploads/2013/02/livro-ISKO-2017.pdf>. Acesso em: 19 mar. 2018.

MELO FILHO, Edilson Targino. Relações teórico-conceituais entre identidade e memória na perspectiva da Ciência da Informação. Informação em Pauta, Fortaleza, v. 1, n. 2, p.116-130, jul. 2016. Disponível em: <http://www.periodicos.ufc.br/informacaoempauta/article/ view/4428/4508>. Acesso em: 21 nov. 2018.

NORA, Pierre. Entre memória e história: a problemática dos lugares. Projeto História, São Paulo, v. 10, p. 7-28, jul./dez. $1993 . \quad$ Disponível em: <http://revistas.pucsp.br/index.php/revph/article/viewFile/12101/8763>. Acesso em: 19 mar. 2018. 
OLIVEIRA, Eliane Braga de. O conceito de memória na Ciência da Informação no Brasil: uma análise da produção científica dos programas de pós-graduação. 2010. 194 f. Tese (Doutorado) - Curso de Ciência da Informação, Universidade de Brasília, Brasília, 2010. Disponível em: <http://repositorio.unb.br/bitstream/10482/7466/1/2010_ElianeBragaOliveira.pdf>. Acesso em: 21 nov. 2018.

OLIVEIRA, Eliane Braga de; RODRIGUES, Georgete Medleg. O conceito de memória na Ciência da Informação: análise das teses e dissertações dos programas de pós-graduação no Brasil. Liinc em Revista, Rio de Janeiro, v. 7, n. 1, p.311-328, mar. 2011. Disponível em: <http://revista.ibict.br/liinc/article/view/3302/2918>. Acesso em: 21 nov. 2018.

PERALTA, Elsa. Abordagens teóricas ao estudo da memória social: uma resenha crítica. Arquivos da Memória: Antropologia, Escala e Memória, Lisboa, n. 2, p. 4-23, 2007. Disponível em: <http://www.fcsh.unl.pt/revistas/arquivos-da-memoria/ArtPDF/02_Elsa_Peralta[1].pdf>.

Acesso em: 07 abr. 2018.

PEREIRA, Felipe Caldonazzo de Almeida; SERAFIM, Jucenir da Silva; MOLINA, Letícia Gorri. Memória para a ciência da informação: um trabalho interdisciplinar. In: SEMINÁRIO DE PESQUISA EM CIÊNCIAS HUMANAS, 11., 2016, São Paulo. Anais... . São Paulo: Blucher, 2016. v. 2, p. 1256 - 1267. Disponível em: <http://pdf.blucher.com.br.s3-sa-east1.amazonaws.com/socialsciencesproceedings/xi-sepech/gt13_163.pdf>. Acesso em: 21 nov. 2018.

PINTO, Tiago Leite; RIBEIRO, Claudio José Silva. O uso de repositórios em Bibliotecas Públicas: um estudo de caso sobre a apropriação da tecnologia para suporte à produção de memória local. In: CONGRESSO BRASILEIRO EM ORGANIZAÇÃO E REPRESENTAÇÃO DO CONHECIMENTO, 4., 2017, Recife. Anais... . Recife: ISKO - Brasil; Ed. UFPE, 2017. p. 279 - 287. Disponível em: <http://isko-brasil.org.br/wp-content/uploads/2013/02/livro-ISKO-2017.pdf>. Acesso em: 19 mar. 2018.

POLLAK, M. Memória, silêncio e esquecimento. Estudos Históricos. Rio de Janeiro, v. 2, n. 3, p. 3-15, 1989.

RICOEUR, Paul. A memória, a história, o esquecimento. Campinas: Ed. da Unicamp, 2007. 535 p.

SARACEVIC, Tefko. Ciência da informação: origem, evolução e relações. Perspectivas em Ciência da Informação. Belo Horizonte, v. 1, n.1, p. 41-62, jan./jul. 1996. Disponível em: <http://portaldeperiodicos.eci.ufmg.br/ index.php/pci/article/view/235/22 >. Acesso em: 27 abr. 2018.

SOUZA, Edivanio Duarte de. A Epistemologia Interdisciplinar na Ciência da Informação: do indícios aos efeitos de sentido na consolidação do campo disciplinar. 2011. 346 f. Tese (Doutorado) - Curso de Ciência da Informação, Escola de Ciência da Informação, Universidade Federal de Minas Gerais, Belo Horizonte, 2011. Disponível em: <http://www.bibliotecadigital.ufmg.br/dspace/bitstream/handle/1843/ECID-8P2JNH/ epistemologia_interdisciplinar_edivanio.pdf?>. Acesso em: 27 abr. 2018.

WERSIG, Gernot; NEVELING, Ulrich. The phenomena of interesting to information science. Information Scientist, v. 9, n. 4, p. 127-140, dez. 1975. Disponível em: <http://sigir.org/files/museum/pub-13/18.pdf>. Acesso em: 12 mar 2018. 
